\title{
Direct Hydrogen Evolution from Sea Water Reduction at Neutral pH using Organic Photocathodes
}

\author{
Marta Haro ${ }^{+}{ }^{[a]}$ Claudia Solis ${ }^{+},{ }^{[b]}$ Vicente M. Blas-Ferrando, ${ }^{[a]}$ Olivier Margeat, ${ }^{[c]}$ Sadok \\ Ben Dhkil, ${ }^{[c]}$ Christine Videlot-Ackermann, ${ }^{[c]}$ Jörg Ackermann, ${ }^{[c]}$ Fabio di Fonzo, ${ }^{[d]}$ \\ Antonio Guerrero, ${ }^{*[a]}$ and Sixto Gimenez ${ }^{*[a]}$
}

\begin{abstract}
Here, we have developed an organic photocathode for water reduction to $\mathrm{H}_{2}$, delivering more than $1 \mathrm{mAcm}^{-2}$ at $0 \mathrm{~V}$ versus RHE and above $3 \mathrm{mAcm}^{-2}$ at $-0.5 \mathrm{~V}$ versus RHE with moderate stability under neutral $\mathrm{pH}$ conditions. The initial competitive reduction of water to $\mathrm{H}_{2}$ and $\mathrm{ZnO}$ to metallic $\mathrm{Zn}$ is responsible for the dynamic behaviour of both photocurrent and Faradaic efficiency of the device, which reaches $100 \%$ Faradaic efficien-
\end{abstract}

cy after 90 min operation. In any case, outstanding stable $\mathrm{H}_{2}$ flow of approximately $2 \mu \mathrm{molh}^{-1}$ is measured over $1 \mathrm{~h}$ at $0 \mathrm{~V}$ versus $\mathrm{RHE}$ and at neutral $\mathrm{pH}$, after equilibrium between the $\mathrm{Zn}^{2+} / \mathrm{Zn}^{0}$ concentration in the AZO film is reached. This achievement opens new avenues for the development of all-solution-processed organic photoelectrochemical cells for the solar generation of $\mathrm{H}_{2}$ from sea water.

\section{Introduction}

Dplease add academic titles (Dr./Prof.) for all authors where appropriate in the author list above. $\square$ The present energy context urgently demands the availability of sustainable and renewable resources to meet the needs of a growing world population with increasing living standards and hence high energy demand. ${ }^{[1]}$ Chemical fuels constitute an attractive energy vector, as they can be easily stored and used upon demand. ${ }^{[2]}$ Consequently, large-scale generation of chemical fuels from decentralized and sustainable resources, like water and sun, is considered one of the key challenges for science and technology. In this context, photoelectrochemical generation of solar fuels with semiconductor materials is a promising

[a] M. Haro, ${ }^{+}$V. M. Blas-Ferrando, A. Guerrero, S. Gimenez Institute of Advanced Materials (INAM)

Universitat Jaume I

12071 Castelló (Spain)

E-mail:aguerrer@uji.es sjulia@uji.es

[b] C. Solis ${ }^{+}$

Universidad Nacional Rio Cuarto

Departamento de Química X5804BYA, Río Cuarto (Argentina)

[c] O. Margeat, S. B. Dhkil, C. Videlot-Ackermann, J. Ackermann Aix-Marseille Université

CNRS, CINaM UMR 7325

13288 Marseille (France)

[d] F. d. Fonzo

Center for Nano Science and Technology@PoliMi

Istituto Italiano di Tecnologia

Via Pascoli $70 / 3$

20133 Milano (Italy)

${ }^{[}{ }^{+}$Both authors have equally contributed to this work.

$\square$ Supporting Information and the ORCID identification number(s) for the

(iD author(s) of this article can be found under http://dx.doi.org/10.1002/ cssc. 201600961.

approach towards the direct conversion of solar energy into chemical fuels. ${ }^{[3]}$ Indeed, competitive solar-to-hydrogen efficiencies over $10 \%$ have been reported for different device architectures using this approach. ${ }^{[4]}$ However, recent techno-economic analysis predicted that the future implementation of this technology will depend on the feasibility of efficient and durable devices targeting $\$ 2-4 \mathrm{~kg}^{-1}$ of dispensed $\mathrm{H}_{2}{ }^{[5]}$ This stringent cost-requirement places low-cost materials and synthetic strategies at the forefront of the research in the field. Additionally, commercial systems should be capable of producing $\mathrm{H}_{2}$ from seawater without any chemical bias.

Semiconducting organic materials (particularly conjugated polymers) have been thoroughly exploited in the field of optoelectronics and photovoltaics. These materials can be processed from solution techniques compatible with low cost manufacturing, such as roll-to-roll processing. ${ }^{[6]}$ Indeed, solarto-electricity efficiencies around $10 \%$ have been achieved for organic photovoltaic (OPV) devices. ${ }^{[7]}$ In contrast, these materials have not received comparable interest for the generation of solar fuels for decades. The first report demonstrating that conjugated polymers can photocatalyze $\mathrm{H}_{2}$ evolution in aqueous solutions containing sacrificial systems was carried out by Yanagida in $1985 .^{[8]}$ Since then, only a few studies have explored the use of these materials for photoelectrochemical generation of solar fuels. ${ }^{[9]}$ In general, immersing organic photoelectrodes in liquid solutions systematically led to very low photocurrents $\left(\approx 1 \mu \mathrm{Acm}^{-2}\right)$ under application of light and electrical bias and the poor stability of these devices rendered reasonable doubts on the origin of the photocurrent. However, it was recently showed that interfacing an OPV with a liquid solution $(0.1 \mathrm{M}$ tetrabutylammonium hexafluorophosphate solution in acetonitrile with a redox pair able to capture either electrons or holes) does not deleteriously affect the photocurrent that the device can deliver in a solid-state configuration, 
and quantitative photocarrier conversion has been demonstrated. ${ }^{[10]}$

Focusing on organic photocathodes for water reduction, some inspiring studies have highlighted the potential of OPVs in acidic environments $(\mathrm{pH} \sim 1)$ and a rapid increase of photocurrent from hundreds of $\mu \mathrm{Acm}^{-2}$ to some $\mathrm{mA} \mathrm{cm}{ }^{-2}$ has been obtained. ${ }^{[11]}$ The basic strategy behind this impressive progress entails the optimization of hole and electron selective contacts to deliver maximum photocurrents, while providing reasonable stability for long-term application. Interestingly, organic photoanodes for water oxidation based on conjugated polymers have been recently reported, ${ }^{[12]}$ opening promising perspectives for the development of all-organic tandem photoelectrochemical water splitting cells.

In a previous study, ${ }^{[11 \mathrm{~d}]}$ we reported stable water reduction photocurrents of $\approx 250 \mu \mathrm{Acm}^{-2}$ for more than $3 \mathrm{~h}(\mathrm{pH} 2)$ by using a cross-linkable poly(3,4-ethylenedioxythiophene)-poly(styrenesulfonate) (PEDOT:PSS) as the hole-selective layer and a $\mathrm{TiO}_{x} / \mathrm{Pt}$ catalytic electron-selective layer sandwiching an archetypical poly(3-hexylthiophene) (P3HT)-phenyl- $\mathrm{C}_{61}$-butyric acid methyl ester (PCBM) blend. The high resistance of the synthesized $\mathrm{TiO}_{x}$ layer has motivated the exploration of more conductive electron-selective layers compatible with operation at neutral $\mathrm{pH}$. In the present study we developed an Al-doped $\mathrm{ZnO}$ (AZO) electron-selective layer prepared by a novel process compatible with low temperature synthesis. We show photocurrents above $1 \mathrm{mAcm}^{-2}$ at $0 \mathrm{~V}$ versus $\mathrm{RHE}\left(\mathrm{V}_{\mathrm{RHE}}\right)$ and above $3 \mathrm{mAcm}^{-2}$ at $-0.5 \mathrm{~V}_{\mathrm{RHE}}$ with moderate stability at neutral $\mathrm{pH}$ conditions, when a C/Pt catalyst is deposited on top of the device. The Faradaic efficiency of the device for water reduction to hydrogen increases with time from $60 \%$ up to $100 \%$ owing to the competitive partial reduction of the selective $\mathrm{ZnO}$ layer to metallic $\mathrm{Zn}$. Although other studies have reported interesting efficiencies for water reduction at neutral $\mathrm{pH}$, they rely on more sophisticated photovoltaic technologies (e.g., CIGS), which employ high-temperature and high-vacuum processing. ${ }^{[13]}$ Consequently, the achievements of the current work open new avenues for the development of all-solution-processed photoelectrochemical cells for the solar generation of $\mathrm{H}_{2}$ from sea water.

The AZO nanocrystals were chemically synthesized through a solution approach that does not require bulky insulating ligands as surfactants, allowing the formation of thin films at a low $85^{\circ} \mathrm{C}$ annealing temperature with improved conductivity compared to $\mathrm{ZnO} .^{[14]}$ Figure 1 a shows a TEM image of the AZO nanoparticles and Figure $1 \mathrm{~b}$ shows an $\mathrm{AZO}$ film observed by SEM. The average diameter of these nanoparticles is $10 \mathrm{~nm}$ and they appear dispersed without agglomeration by dynamic light scattering measurements. The Al-doping level of $0.8 \%$ was determined by inductively coupled plasma mass spectrometry (ICP-MS) analyses. Powder X-ray diffraction (PXRD) patterns shown in the Supporting Information (Figure SI1) highlight the crystalline nature of the nanocrystals generated using this synthetic procedure. The work function is $4.08 \mathrm{eV}$ with conduction band energy of $3.79 \mathrm{eV}$ and ionization potential of $7.87 \mathrm{eV}$ as determined in Ref. [14]. These values suggest that AZO is a promising candidate to be used as an electron-
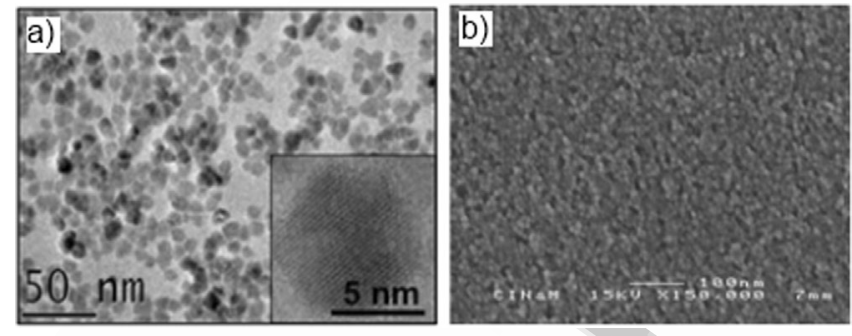

Figure 1. a) TEM and b) SEM images of the AZO nanoparticles.

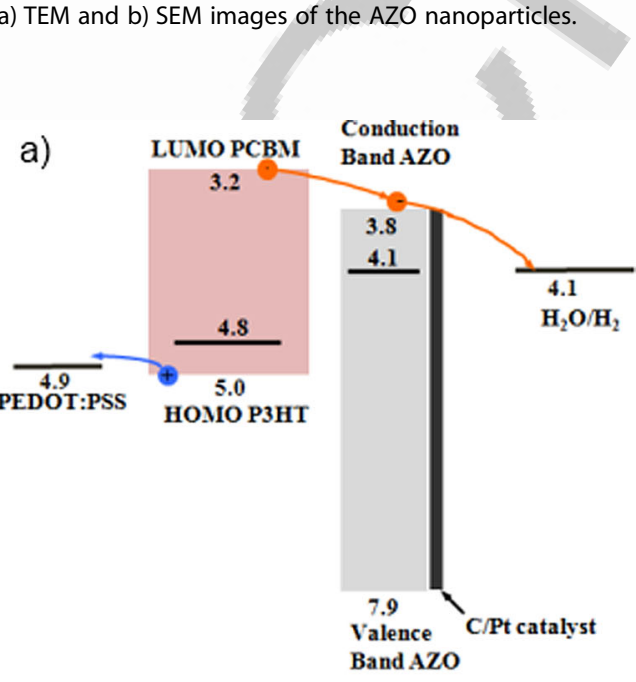

a)

b)

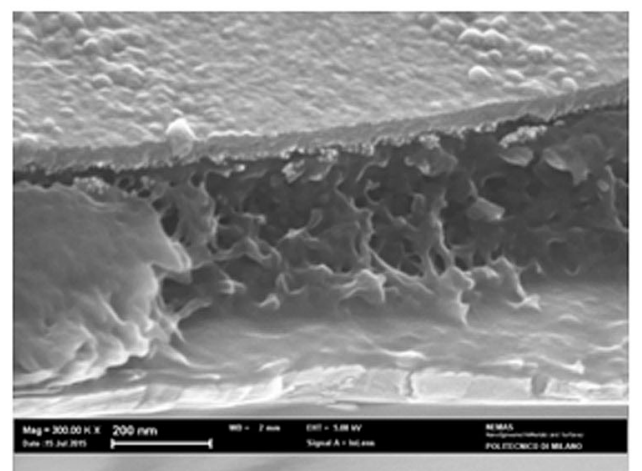

Figure 2. a) Energy diagram of the device with architecture ITO/x-PEDOT/ $\mathrm{BHJ} / \mathrm{AZO} / \mathrm{C} / \mathrm{Pt}$ and pathway for electrons resulting in water reduction to $\mathrm{H}_{2}$. b) SEM of the cross-section of a full device.

selective layer in organic photoelectrochemical devices and an illustrative energy diagram of the full device is showed as Figure $2 \mathrm{a}$. Average mobility values of $\mu=2 \times 10^{-5} \mathrm{~cm}^{2} \mathrm{Vs}^{-1}$ were extracted from field-effect transistors measurements (see Figures $\mathrm{SI} 2$ and $\mathrm{SI} 3$ for details). Although this is not an extremely high value, it is adequate to be used in devices with a few tens of nanometers.

A representative cross-sectional micrograph of the full $x$ PEDOT $\square$ what does the $x$ represent? This has not yet been defined. $\mathbf{\square}$ / $\mathbf{\square}$ please define BHJ here. Bulk heterojunction? between what and what? $\mathbf{\square}(\mathrm{BHJ}) / \mathrm{AZO} / \mathrm{C} / \mathrm{Pt}$ device is shown in Figure $2 \mathrm{~b}$. The AZO layer appears as a nanoparticulated film on top of the device, coated by $\mathrm{a} \sim 1 \mathrm{~nm}$ thick layer of the C/Pt catalyst. The thicknesses of the $x$-PEDOT, BHJ, and 
AZO layers have been estimated as 40,300 , and $40 \mathrm{~nm}$, respectively. The C/Pt catalytic layer is below $1 \mathrm{~nm}$ and cannot be identified by SEM.

The full devices were tested for $\mathrm{H}_{2}$ evolution under acidic conditions ( $\mathrm{pH} 2$ and 5) showing poor performance (after the first cyclic voltammetry scan) and stability as shown in Figure SI4. This is in good correlation with the Pourbaix diagram of $\mathrm{ZnO}{ }^{[15]}$ Then, the photoelectrochemical behavior of the de-
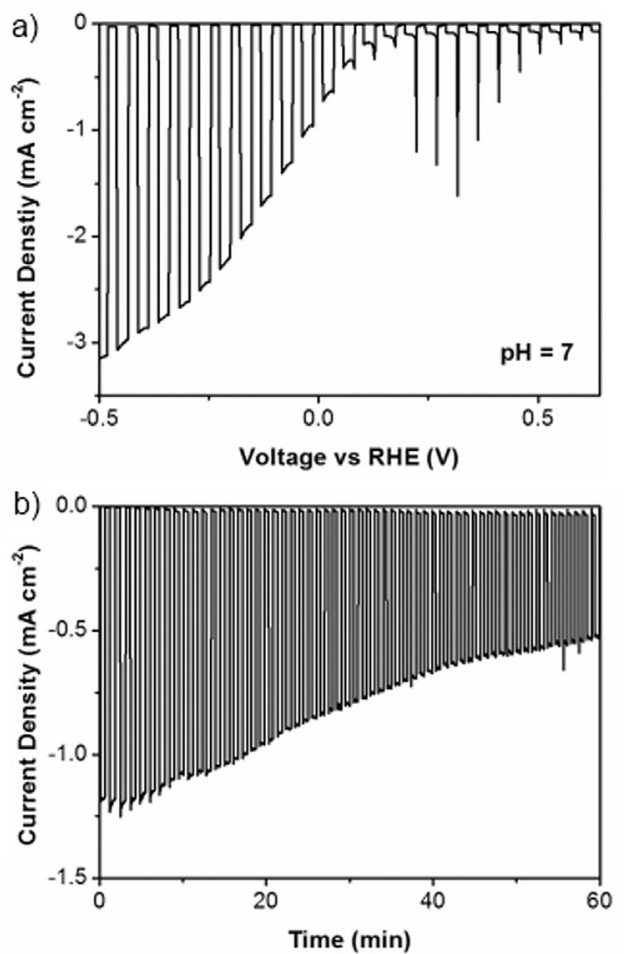

Figure 3. a) $j-V$ plot for $x$-PEDOT/BHJ/AZO/C/Pt at $\mathrm{pH} 7$ at a scan speed of $5 \mathrm{mV} \mathrm{s}^{-1}$. b) $j-t$ plot at $V_{\text {bias }}=0 V_{\text {RHE }}$. vices for water reduction at neutral $\mathrm{pH}(\mathrm{pH} 6.9)$ was investigated and the results are showed in Figure 3. Figure 3 a shows the current-voltage $(j-V)$ curve under chopped illumination, achieving remarkable photocurrents of $1.2 \mathrm{mAcm}^{-2}$ at $0 \mathrm{~V}_{\mathrm{RHE}}$ and above $3 \mathrm{mAcm}^{-2}$ at $-0.5 \mathrm{~V}_{\mathrm{RHE}}$. At the most positive values of potential showed in Figure $3 \mathrm{a}$, cathodic spikes indicative of electron accumulation are observed ${ }_{r}^{[16]}$ but at potentials more negative than $0 \mathrm{~V}_{\mathrm{RHE}}$, the spikes are not any longer visible, reflecting the fully faradaic nature of the photocurrent. Compared to the pure Pt catalyst, the use of C/Pt notably improves the performance of the photocathode (see Figure SI5). This enhanced behavior can be ascribed to two different reasons. First, the size of the Pt nanoparticles is reduced, as nanoparticle aggregation is hampered by the presence of the carbon layer. ${ }^{[17]}$ On the other hand, the carbon layer acts as an efficient electron scavenger from the oxide film, ${ }_{1}^{[18]}$ improving both the charge-transfer kinetics (catalytic efficiency) and the long-term stability. The stability of the devices was studied by chronoamperometric measurements at $0 \mathrm{~V}_{\mathrm{RHE}}$ and the obtained results are shown in Figure $3 \mathrm{~b}$. After 60 min chopped illumination, the photocurrent decreases $50 \%$, but from this time on, the decrease is much more moderate, around $5 \%$ over the next $60 \mathrm{~min}$, as can be seen in Figure SI6.

To gain insights into the time evolution of the photocurrent, surface characterization on pristine and aged devices (after $1 \mathrm{~h}$ testing at $\mathrm{pH} 7$ ) was carried out by X-ray photoelectron spectroscopy (XPS, Figures 4 SI7). Typical XPS spectra for the Zn $2 p$ electrons before and after chronoamperometric testing are shown as Figure $4 a$ and $b$, respectively. These spectra suggest some changes in the electronic structure of $\mathrm{Zn}$. More conclusive information can be obtained from the Auger spectra showed in Figure $4 \mathrm{c}$ and $d$. The $\mathrm{Zn} \mathrm{L}_{3} \mathrm{M}_{45} \mathrm{M}_{45}$ Auger line measured with $\mathrm{Al}-\mathrm{K} \alpha$ photons allows monitoring different $\mathrm{Zn}$ oxidation states, owing to the pronounced difference between positions and line shapes for both $\mathrm{Zn}$ and $\mathrm{ZnO}$ spectral com-
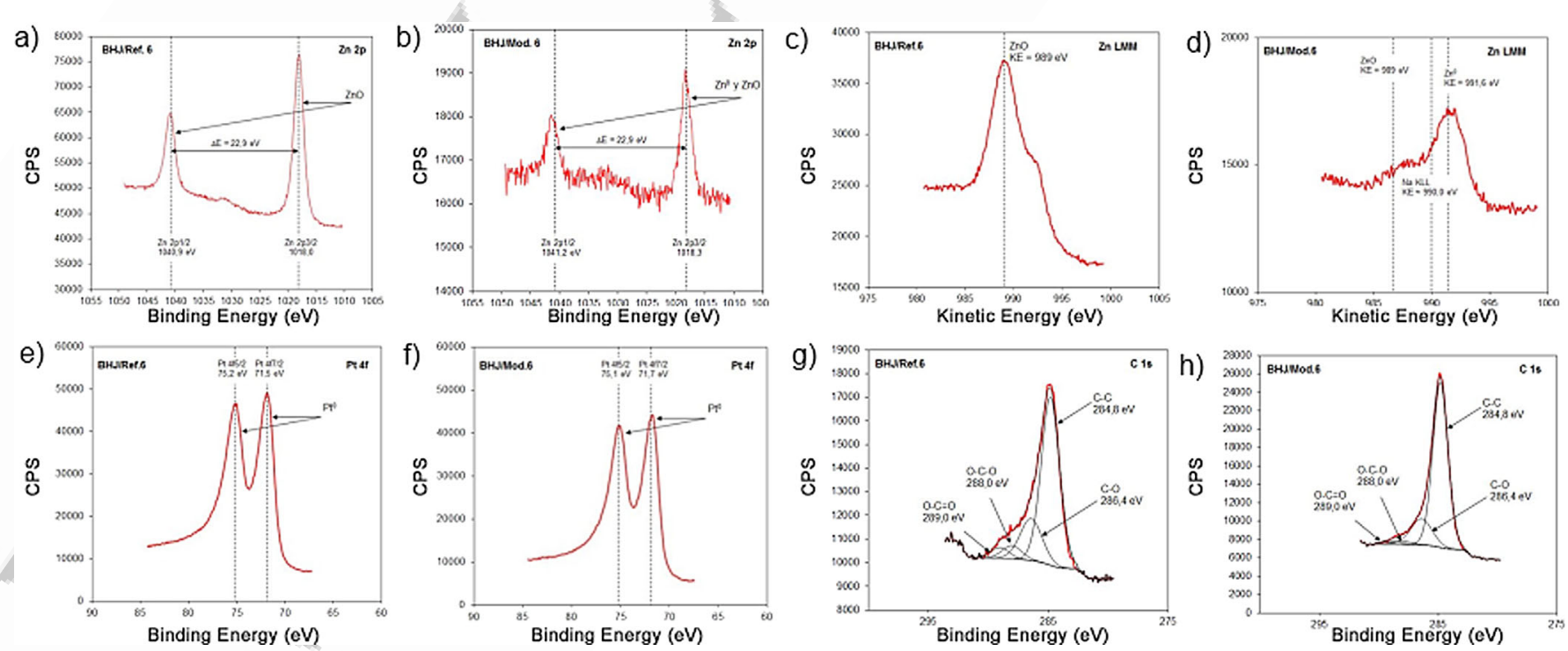

Figure 4. XPS spectra obtained from a $x$-PEDOT/BHJ/AZO/C/Pt device $a, c, e)$ before and $b, d, f$ after chronoamperometric testing over $1 \mathrm{~h}$ at $\mathrm{pH} 7 \mathrm{hnder}$ chopped illumination. a-b) Zn 2p signal, c-d) Zn Auger signal, e-f) Pt $4 f$ signal, g-h) C 1s signal. 
ponents. ${ }^{[19]}$ The results show that $\mathrm{Zn}$ is present as $\mathrm{ZnO}$ in the pristine sample, but a component of metallic $\mathrm{Zn}$ is detected after the chronoamperometric test, clearly indicating partial reduction of the metallic oxide upon operation under cathodic photocurrent. On the other hand, both the XPS spectra for Pt 4f (Figure $4 \mathrm{e}-\mathrm{f}$ ) and $\mathrm{C} 1 \mathrm{~s}$ (Figure $4 \mathrm{~g}-\mathrm{h}$ ) show that the C/Pt catalyst does not suffer significant degradation during operation for $1 \mathrm{~h}$ at neutral $\mathrm{pH}$.

Finally, $\mathrm{H}_{2}$ production was evaluated by carrying out the measurements in a sealed cell where the output gas flow was periodically analyzed by gas chromatography, Figure $5 \mathrm{a}$. Consistent with the results obtained from XPS (Figure 4), the electrode evolves during the first $90 \mathrm{~min}$. Initially, the production

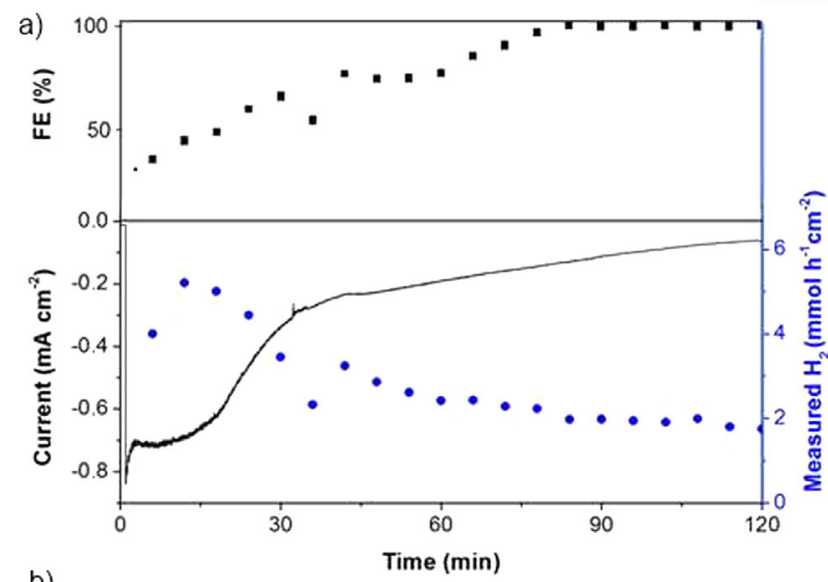

b)
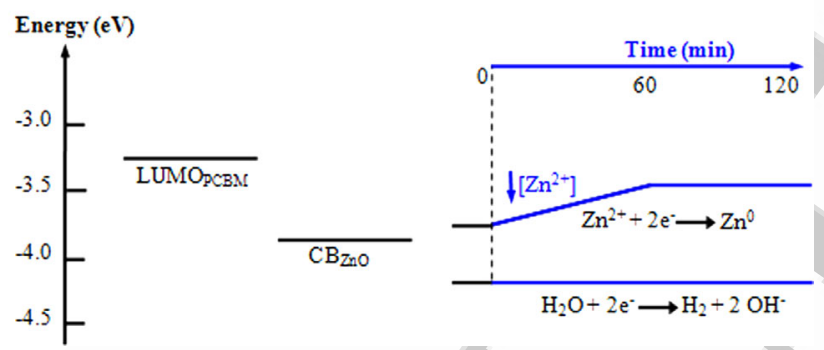

Figure 5. a) $\mathrm{H}_{2}$ evolution for the system $x$-PEDOT/BHJ/AZO/C/Pt at $\mathrm{pH} 7$, the measured photocurrent and the Faradaic efficiency. b) Energetic model of the photogenerated electrons at the electrode/electrolyte interface and the evolution of the energetic levels of the electrolyte with time, during $\mathrm{H}_{2}$ generation. The redox potential of water reduction is corrected to $\mathrm{pH} 6.9$.

of $\mathrm{H}_{2}\left(\approx 5 \mu \mathrm{molh} \mathrm{h}^{-1} \mathrm{~cm}^{-2}\right)$ is high, in agreement to the measured values of photocurrent. However, less than $60 \%$ of the photogenerated electrons are reducing water efficiently according to the calculated Faradaic efficiency. The rest of photogenerated electrons in the organic blend are injected into the AZO film with the subsequent $\mathrm{Zn}^{2+}$ reduction to $\mathrm{Zn}^{0}$, as clearly suggested by Auger spectroscopy (Figures $4 c-d$ ). This behavior is more noticeable during the first $15 \mathrm{~min}$. After this period, the photocurrent decreases while the Faradaic efficiency increases, indicating that the photogenerated electrons are more effectively directed to the water reduction reaction compared to the competitive reduction of $\mathrm{Zn}^{2+}$. An equilibrium situation is reached after $60 \mathrm{~min}$, with the measurement of a stable pho- tocurrent and an $\mathrm{H}_{2}$ flow of approximately $2 \mu \mathrm{molh}^{-1} \mathrm{~cm}^{-2}$ during the next hour, and a Faradaic efficiency of $100 \%$ after $90 \mathrm{~min}$.

These results can be easily explained by the energetic diagram shown in Figure $5 \mathrm{~b}$. In this diagram, the energy levels for both $\mathrm{Zn}^{2+}$ and $\mathrm{H}_{2} \mathrm{O}$ reduction are included and we consider that both reduction reactions below [Eqs. (1) and (2)] are competitive.

$2 \mathrm{H}_{2} \mathrm{O}+2 e^{-} \rightarrow \mathrm{H}_{2}+2 \mathrm{OH}^{-}$
$\mathrm{Zn}^{2+}+2 e^{-} \rightarrow \mathrm{Zn}^{0}$

The photogenerated electrons within the organic blend are collected at the LUMO band of the acceptor (PCBM). In contact with the organic blend ( $p$-type semiconductor), the layer of AZO (n-type semiconductor) provides an excellent electron-selective contact for the formation of a rectifying $p-n$ junction, which assists the extraction of the photogenerated electrons, with adequate energy to reduce both water to $\mathrm{H}_{2}$ [Eq. (1)] and the $\mathrm{Zn}^{2+}$ cations of the AZO layer to $\mathrm{Zn}^{0}$ [Eq. (2)]. Initially, the reduction of $\mathrm{Zn}^{2+}$ is favored (time 0 in Figure $5 \mathrm{~b}$ ), and the decrease of the $\mathrm{Zn}^{2+}$ concentration shifts the redox potential of Eq. (2) to higher values according to the Nernst equation (slope $=0.029 \log \left[\mathrm{Zn}^{2+}\right]$ ) पok? until equilibrium is reached and no further net $\mathrm{Zn}^{2+}$ reduction takes place. Then, all photogenerated electrons follow the desired hydrogen evolution reaction [Eq. (1)]. In the real device, the energetic diagram is more complex compared to that shown in Figure $5 \mathrm{~b}$, because the $\mathrm{Zn}^{2+}$ ions are present in the AZO layer (not in the electrolyte). In any case, the electrode surface is significantly affected as shown by surface analysis, and the simplified energy diagram of Figure $5 \mathrm{~b}$ can reasonably explain the evolution of the electrode with time (Figure $5 \mathrm{a}$ ). Although we use a C/Pt catalyst deposited by sputtering to analyze the response of the engineered photocathodes, to minimize losses at the semiconductor/solution interface, the basic device configuration is solution processed (photoactive material and selective contacts). Consequently, as far as the authors know, this is the first time that $\mathrm{H}_{2}$ generation with a solution-processed organic photoelectrochemical system at neutral $\mathrm{pH}$ is reported.

\section{Conclusions}

We have developed an organic photoelectrochemical device able to reach photocurrents of more than $1 \mathrm{mAcm}^{-2}$ at $0 \mathrm{~V}$ versus $\mathrm{RHE}$, with reasonable stability under neutral $\mathrm{pH}$ conditions. The achieved performance is based on the use of an AZO nanoparticulated layer as an electron-selective contact, allowing device operation at neutral $\mathrm{pH}$. Furthermore, we have clarified the origin of the evolution of photocurrent and Faradaic efficiency with time. The initial competitive reduction of both water and the AZO layer is responsible for the increased Faradaic efficiency from $60 \%$ to up to $100 \%$ after 90 min operation. Noteworthy after $1 \mathrm{~h}$ of operation of the device, a quite stable $\mathrm{H}_{2}$ flow of approximately $2 \mu \mathrm{mol} \mathrm{h}^{-1} \mathrm{~g}^{-1}$ is obtained for $1 \mathrm{~h}$. These results highlight the versatility and potential of or- 
ganic photoelectrochemical devices as a real low-cost alternative for the generation of solar fuels.

\section{Acknowledgements}

We thank financial support from Generalitat Valenciana (ISIC) 2012/008 Institute of Nanotechnologies for Clean Energies). We acknowledge the financial support of the European Community through the Future and Emerging Technologies (FET) programme under the FP7, collaborative Project contract $n^{\circ} 309223$ (PHOCS). Additionally, the EU projects "Sunflower" (FP7-ICT-2011-7- contract num. 287594) and the SFUMATO-FUI Project AAP12 are acknowledged. A.G. would like to thank the Spanish Ministerio de Economía y Competitividad for a Ramón y Cajal Fellowship (RYC2014-16809).

Keywords: hydrogen - organic photoelectrochemical cells selective contacts $\cdot$ solar fuels $\cdot$ water splitting

[1] M. Meinshausen, N. Meinshausen, W. Hare, S. C. B. Raper, K. Frieler, R. Knutti, D. J. Frame, M. R. Allen, Nature 2009, 458, 1158-1162.

[2] S. Chu, A. Majumdar, Nature 2012, 488, 294- 303.

[3] T. Hisatomi, J. Kubota, K. Domen, Chem. Soc. Rev. 2014, 43, 7520-7535.

[4] a) O. Khaselev, J. A. Turner, Science 1998, 280, 425-427; b) J. Luo, J.-H. Im, M. T. Mayer, M. Schreier, M. K. Nazeeruddin, N.-G. Park, S. D. Tilley, H. J. Fan, M. Graetzel, Science 2014, 345, 1593-1596.

[5] B. A. Pinaud, J. D. Benck, L. C. Seitz, A. J. Forman, Z. Chen, T. G. Deutsch, B. D. James, K. N. Baum, G. N. Baum, S. Ardo, H. Wang, E. Miller, T. F. Jaramillo, Energy Environ. Sci. 2013, 6, 1983-2002.

[6] F. C. Krebs, S. A. Gevorgyan, J. Alstrup, J. Mater. Chem. 2009, 19, 5442 5451.

[7] a) H. J. Park, J. Y. Lee, T. Lee, L. J. Guo, Adv. Energy Mater. 2013, 3, 1135 1142 ; b) Z. He, C. Zhong, S. Su, M. Xu, H. Wu, Y. Cao, Nat. Photonics 2012, 6, $591-595$.

[8] S. Yanagida, A. Kabumoto, K. Mizumoto, C. Pac, K. Yoshino, J. Chem. Soc Chem. Commun. 1985, 474-475.

[9] a) O. A. El-Rashiedy, S. Holdcroft, J. Phys. Chem. 1996, 100, 5481-5484; b) E. Lanzarini, M. R. Antognazza, M. Biso, A. Ansaldo, L. Laudato, P.
Bruno, P. Metrangolo, G. Resnati, D. Ricci, G. Lanzani, J. Phys. Chem. C 2012, 116, 10944-10949.

[10] A. Guerrero, M. Haro, S. Bellani, M. R. Antognazza, L. Meda, S. Gimenez, J. Bisquert, Energy Environ. Sci. 2014, 7, 3666.

[11] a) T. Bourgeteau, D. Tondelier, B. Geffroy, R. Brisse, R. Cornut, V. Artero, B. Jousselme, ACS Appl. Mater. Interfaces 2015, 7, 16395-16403; b) T. Bourgeteau, D. Tondelier, B. Geffroy, R. Brisse, C. Laberty-Robert, S. Campidelli, R. de Bettignies, V. Artero, S. Palacin, B. Jousselme in Energy \& Environmental Science, Vol. 6, The Royal Society of Chemistry, London, 2013 pp. 2706-2713; c) F. Fumagalli, S. Bellani, M. Schreier, S. Leonardi, H. Comas Rojas, A. Ghadirzadeh, G. Tullii, A. Savoini, G. Marra, L. Meda, M. Gratzel, G. Lanzani, M. T. Mayer, M. R. Antognazza, F. Di Fonzo, J. Mater. Chem. A 2016; d) M. Haro, C. Solis, G. Molina, L. Otero, J. Bisquert, S. Gimenez, A. Guerrero, J. Phys. Chem. C 2015, 119, 6488-6494; e) T. Bourgeteau, D. Tondelier, B. Geffroy, R. Brisse, S. Campidelli, R. Cornut, B. Jousselme, J. Mater. Chem. A 2016, 4, 4831-4839; f) H. Comas Rojas, S. Bellani, F. Fumagalli, G. Tullii, S. Leonardi, M. T. Mayer, M. Schreier, M. Gratzel, G. Lanzani, F. Di Fonzo, M. R. Antognazza, Energy Environ. Sci. DOI: 10.1039/c6ee01655c. —Please provide details for Ref. 11 c (vol/ page numbers or DOI) $\mathbf{\square}$

[12] P. Bornoz, M. S. Prevot, X. Yu, N. Guijarro, K. Sivula, J. Am. Chem. Soc. 2015, 137, 15338-15341.

[13] H. Kumagai, T. Minegishi, N. Sato, T. Yamada, J. Kubota, K. Domen, J. Mater. Chem. A 2015, 3, 8300-8307.

[14] M. Gaceur, S. B. Dkhil, D. Duche, F. Bencheikh, J.-J. Simon, L. Escoubas, M. Mansour, A. Guerrero, G. Garcia-Belmonte, X. Liu, M. Fahlman, W. Dachraoui, A. K. Diallo, C. Videlot-Ackermann, O. Margeat, J. Ackermann, Adv. Funct. Mater. 2016, 26, 243-253.

[15] T. K. A. Hoang, T. N. L. Doan, K. E. K. Sun, P. Chen, RSC Adv. 2015, 5, $41677-41691$.

[16] B. Klahr, S. Gimenez, F. Fabregat-Santiago, J. Bisquert, T. W. Hamann, Energy Environ. Sci. 2012, 5, 7626-7636.

[17] R. Kou, Y. Shao, D. Wang, M. H. Engelhard, J. H. Kwak, J. Wang, V. V. Viswanathan, C. Wang, Y. Lin, Y. Wang, Electrochem. Commun. 2009, 11, 954-957.

[18] M. Haro, L. F. Velasco, C. O. Ania, Catal. Sci. Technol. 2012, 2, 2264-2272.

[19] a) G. Schön, J. Electron Spectrosc. Relat. Phenom. 1973, 2, 75-86; b) I. Valenti, S. Benedetti, A. di Bona, S. Valeri, J. Phys. Chem. C 2015, 119, $13743-13749$.

Received: July 18, 2016

Published online on $\mathbf{\square}$ uI, 0000 


\section{FULL PAPERS}

M. Haro, C. Solis, V. M. Blas-Ferrando,

O. Margeat, S. B. Dhkil,

C. Videlot-Ackermann, J. Ackermann,

F. d. Fonzo, A. Guerrero, ${ }^{*}$ S. Gimenez*

$\square-\square$

Direct Hydrogen Evolution from Sea

Water Reduction at Neutral pH using Organic Photocathodes

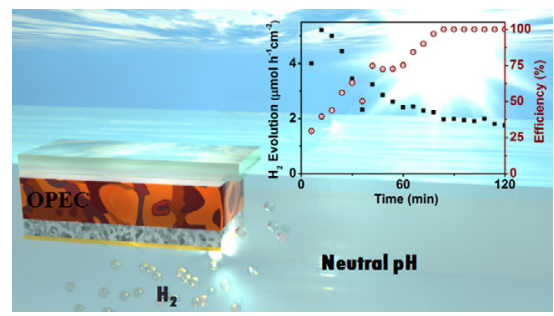

Neutral $\mathrm{pH}_{2}$ : The development of an organic photocathode with engineered interfacial selective layers is described towards direct $\mathrm{H}_{2}$ generation from saline water at neutral $\mathrm{pH}$ using solar energy. The electron-selective layer based on ZnO doped with Al (AZO) is the key towards operation under neutral $\mathrm{pH}$ conditions. Once the system is at equilibrium, a flow of approximately $2 \mu \mathrm{mol} \mathrm{h}^{-1}$ is measured over $1 \mathrm{~h}$ at $0 \mathrm{~V}$ versus RHE.

\#Hydrogenevolution from \#watersplitting at neutral pH using organic \#seaweater and \#photocathodes SPACE RESERVED FOR IMAGE AND LINK

Share your work on social media! ChemSusChem has added Twitter as a means to promote your article. Twitter is an online microblogging service that enables its users to send and read text-based messages of up to 140 characters, known as "tweets". Please check the pre-written tweet in the galley proofs for accuracy. Should you or your institute have a Twitter account, please let us know the appropriate username (i.e., @accountname), and we will do our best to include this information in the tweet. This tweet will be posted to the journal's Twitter account @ChemSusChem (follow us!) upon online publication of your article, and we recommended you to repost ("retweet") it to alert other researchers about your publication.

Please check that the ORCID identifiers listed below are correct. We encourage all authors to provide an ORCID identifier for each coauthor. ORCID is a registry that provides researchers with a unique digital identifier. Some funding agencies recommend or even require the inclusion of ORCID IDs in all published articles, and authors should consult their funding agency guidelines for details. Registration is easy and free; for further information, see http://orcid.org/.

Marta Haro

Claudia Solis

Vicente M. Blas-Ferrando

Olivier Margeat

Sadok Ben Dhkil

Christine Videlot-Ackermann

Jörg Ackermann

Fabio di Fonzo

Antonio Guerrero

Sixto Gimenez http://orcid.org/0000-0002-4522-3174 